\title{
Storage of Decapsulated Artemia (Brine Shrimp) ${ }^{1}$
}

\author{
Jason Broach, Cortney Ohs, and Isaac Lee ${ }^{2}$
}

Artemia (brine shrimp) are used as a food source for the larval stages of many fishes. Artemia are predominantly collected from the wild during their cyst stage and are dried and stored in air-tight, sealed containers. The cysts are decapsulated before they are stocked to improve hatch rates of the Artemia nauplii and to prevent larval fish from ingesting cysts, which are not digestible to many species. Many hatcheries use the chlorine method described in Decapsulating Brine Shrimp Eggs. This method is effective, but like others, it can be time- and labor-consuming if performed on a daily basis. Fortunately, there are methods to store decapsulated Artemia eggs for a short time period and eliminate the need to decapsulate daily.

Decapsulated Artemia eggs can be stored in brine solution for a period of a week or more with limited effects on hatching success. By using this method, it's possible to decapsulate a single large quantity of Artemia cysts to supply required larval feedings for a week or more. As an example, if a producer requires $5 \mathrm{~g}$ of Artemia cysts to complete one day of feedings, then $35 \mathrm{~g}$ of cysts could be decapsulated and brined to supply a full week's feedings.

The required materials to complete the steps for storage in a brine solution are:

- Decapsulated Artemia eggs

- Rock salt

- Artemia hatching cone or similar container
- Artemia net or screened containers $(\leq 100 \mu \mathrm{m})$

- Scale (0.1-300 g)

- Graduated containers (100 mL to $10 \mathrm{~L}$ )

\section{Brining Steps}

1. Create a brine solution of $300 \mathrm{ppt}(\mathrm{g} / \mathrm{L})$. Mix $300 \mathrm{~g}$ of rock salt in $1 \mathrm{~L}$ of tap water (or 1,136 g of rock salt with 1 gallon of tap water). Mixing the solution using warm tap water within a hatching cone with heavy aeration can facilitate the dissolving of the salt into the water (Figure 1). The volume of brine solution needed will depend on the quantity of eggs being brined, but $1 \mathrm{~L}$ should be adequate for every $10 \mathrm{~g}$ of eggs to be brined. Always mix extra so that fresh brine solution can be set aside and kept available for rinsing and use in storage containers once the brining process is complete.

2. Remove as much of the water left over from decapsulation as possible. Stock concentrated, decapsulated eggs into the brine solution in a hatching cone with moderate to heavy aeration. Incubate for 16-24 hours at room temperature.

3. Harvest and concentrate the brined eggs into a screened container or Artemia net to remove nearly all the old brine solution (Figure 2).

1. This document is FA203, one of a series of the School of Forest Resources and Conservation, Program in Fisheries and Aquatic Sciences, UF/IFAS Extension. Original publication date April 2018. Visit the EDIS website at http://edis.ifas.ufl.edu.

2. Jason Broach, post doctoral assistant; Cortney Ohs, aquaculture specialist, UF/IFAS Extension Florida Sea Grant College Program; and Isaac Lee, graduate assistant, School of Forest Resources and Conservation, Program in Fisheries and Aquatic Sciences; UF/IFAS Indian River Research and Education Center, Fort Pierce, FL 34945-3138.

The Institute of Food and Agricultural Sciences (IFAS) is an Equal Opportunity Institution authorized to provide research, educational information and other services only to individuals and institutions that function with non-discrimination with respect to race, creed, color, religion, age, disability, sex, sexual orientation, marital status, national origin, political opinions or affiliations. For more information on obtaining other UF/IFAS Extension publications, contact your county's UF/IFAS Extension office. 
4. Using fresh brine solution, rinse the eggs into a graduated container of brine solution and top off to a desired total volume (Figure 3).

5. Divide the solution of brined eggs into smaller-aliquot containers of desired quantities and top off with brine solution to fill containers to desired volumes.

6. Store in a refrigerator at approximately $4.0^{\circ} \mathrm{C}$ for up to a week to maintain high hatching success (Figure 4).

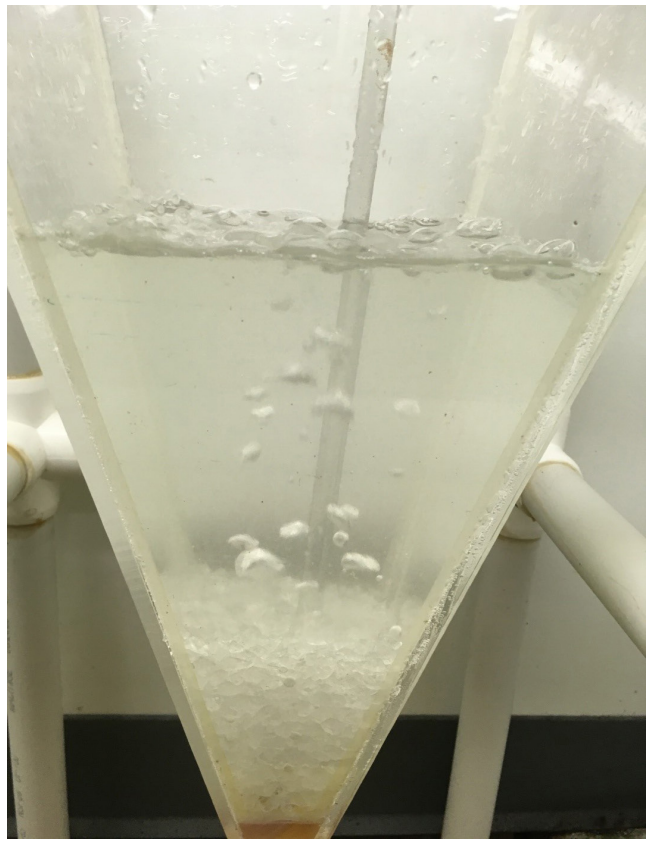

Figure 1. Rock salt being dissolved in freshwater within a hatching cone to create a brine solution of $300 \mathrm{ppt}(\mathrm{g} / \mathrm{L})$.

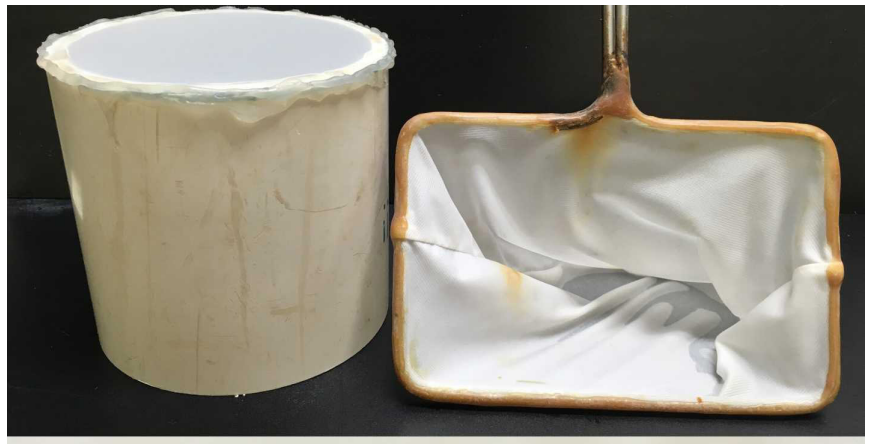

Figure 2. Screened containers and nets (top image) used for harvesting and concentrating Artemia eggs (bottom image).

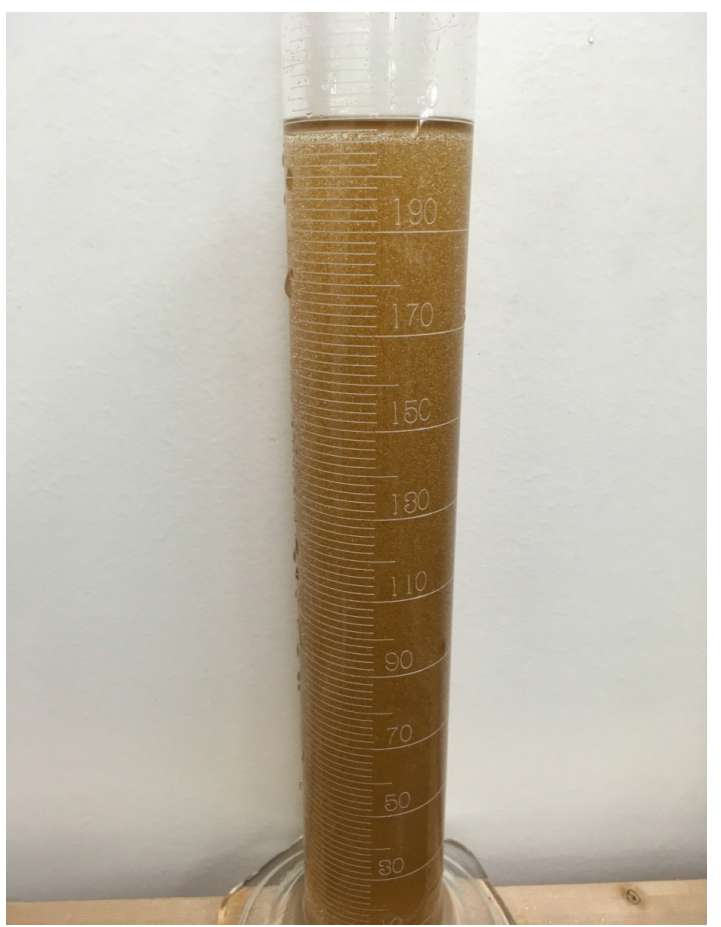

Figure 3. Freshly brined and evenly distributed Artemia eggs within a graduated cylinder used for equal dispersal of eggs into storage containers. In this case, $210 \mathrm{~mL}$ of brined eggs could be split into seven equal quantities of $30 \mathrm{~mL}$ each.

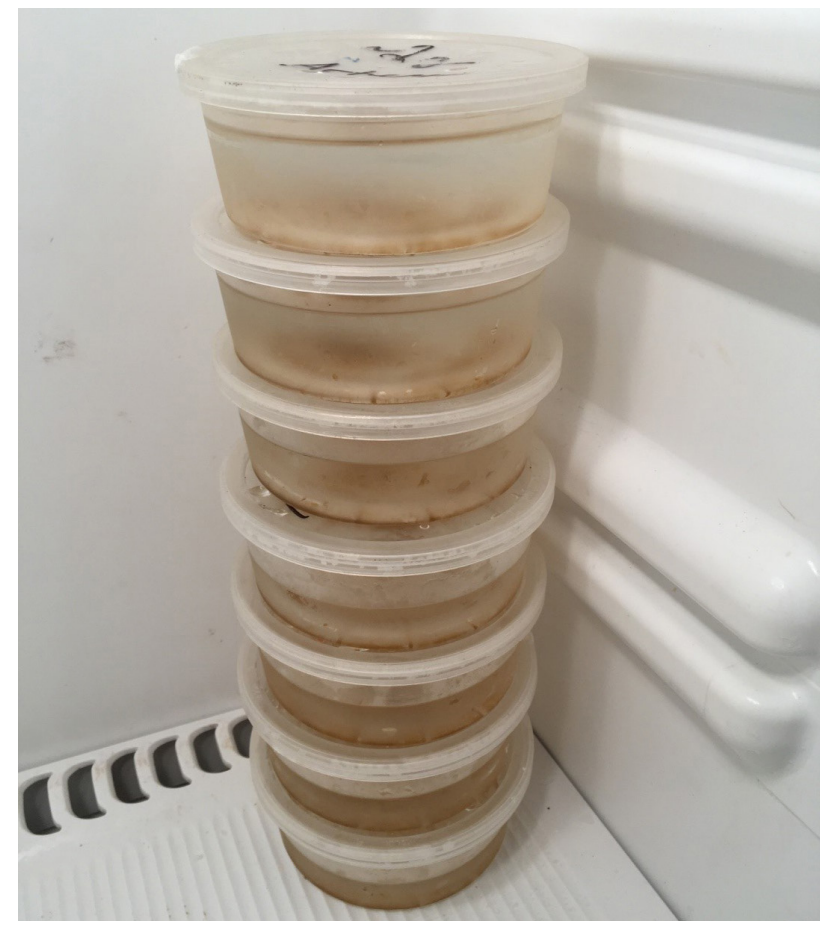

Figure 4. Artemia eggs of equal quantites stored in brine solution within a refrigerator.

\section{Storage Recommendations}

Brined Artemia eggs can be stored all in one container or split into multiple containers as aliquots to be hatched daily, or at more or less frequent intervals. If one intends to have an aliquot container for each day of the week and use seven containers, knowing the total volume of the solution 
of brined eggs within the large container will facilitate dividing all the brined eggs into the seven smaller aliquots. For example, if there were a 2,100 $\mathrm{mL}$ solution of $35 \mathrm{~g}$ of brined eggs, it could be split for daily hatching into seven, $300 \mathrm{~mL}$ quantities, each containing $5 \mathrm{~g}$ of brined eggs. Alternatively, the $2,100 \mathrm{~mL}$ solution could be stored in the refrigerator and $300 \mathrm{~mL}$ poured off from the container after homogenization to obtain the $5 \mathrm{~g}$ of brined eggs as needed. Brined eggs will settle to the bottom when left static in brine solution (Figure 5), so it is important to keep the solution homogenized as the eggs are being split into smaller containers to achieve equal amounts of eggs in each of the containers.

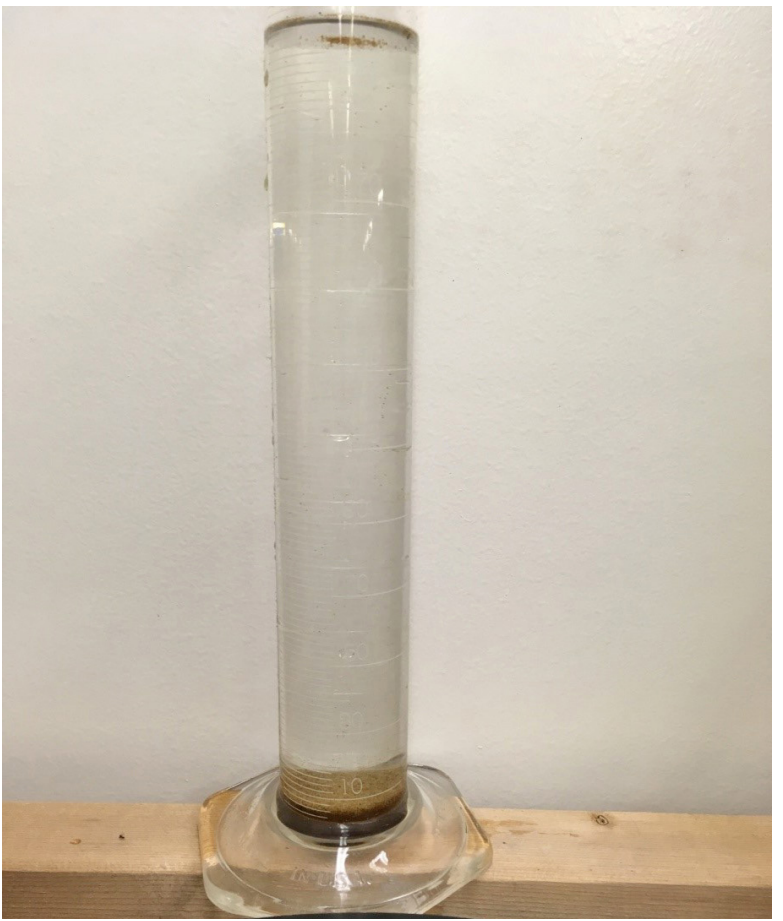

Figure 5. Artemia eggs left undisturbed for a few minutes and allowed to settle to the bottom of a graduated cylinder.

\section{Other Notes}

When stocking brined eggs for hatching, introduce as little of the brine solution as possible so as to not alter the desired salinity to be used for hatching. This can be achieved by concentrating the brined eggs into nets or on screens, or decanting off the brine solution from static solutions of brined eggs. 